www.jmscr.igmpublication.org

Impact Factor (SJIF): 6.379

Index Copernicus Value: 71.58

ISSN (e)-2347-176x ISSN (p) 2455-0450

crossref DOI:_https://dx.doi.org/10.18535/jmscr/v6i2.06

Journal Of Medical Science And Clinical Research

IGM Publication

An official Publication of IGM Publication

\title{
Clinical Paper \\ Efficacy of Peri-Operative Intercostal Nerve Blockade in Standard PCNL- A Prospective Cohort Study
}

\author{
Authors \\ Dr A T Rajeevan ${ }^{1}$, Dr Shanmughadas K V ${ }^{2}$, Dr Piyush Gupta ${ }^{3}$, Dr Felix Cardoza \\ ${ }^{1,2}$ Additional Professor, Department of Urology, Government Medical College, Calicut, Kerala \\ ${ }^{3}$ Senior Resident, Department of Urology, Government Medical College, Calicut, Kerala \\ ${ }^{4}$ Professor, Department of Urology, Government Medical College, Calicut, Kerala \\ Corresponding Author \\ Dr Shanmughadas K V
}

Department of Urology, Government Medical College, Calicut, Kerala- 673008

Email:drpiyush2202@yahoo.co.in, Mobile No.09895096730

\begin{abstract}
Introduction and Aim: Percutaneous nephrolithotomy (PCNL) has become the GOLD standard for the management of renal calculi. But pain in the immediate post-op period especiallyin institutions where Standard PCNL is still being done as a routine, can be quite severe, requiring opioid administration. Intercostal Nerve Blockade (INB) is an effective way to optimize pain control and to reduce the need for opioid administration in the post-operative period in such patients. We aimed to evaluate the role of INB in Standard PCNL in terms of post-operative analgesia requirement, speed of mobilization and total duration of inpatient stay.

Methods: 60 patients undergoing elective standard PCNL were divided into Study group or Group $S$ (0.25\% bupivacaine infiltration) and Control group or Group C (without infiltration). Percutaneous INB was done in the study group at the end of the procedure prior to the patient being turned supine. The three intercostal nerves supplying the dermatomes within which the incisions were made were blocked. At each site, $5 \mathrm{ml}$ of $0.25 \%$ bupivacaine in group $S$ was infiltrated. Postoperative pain was assessed by visual analogue scale (VAS) at rest \{score between 0 and 10\} and dynamic visual analogue scale (DVAS) during deep breathing and coughing \{score between 0 and 10\} every 4 hours for first 24 hours. Intravenous tramadol was given as rescue analgesia when VAS score was >4. Time to first rescue analgesic and total amount of tramadol required in first 24 hours were noted.

Results: VAS and DVAS scores in Group $S$ were significantly lower ( $p<0.05)$ than Group C till first 16 hours. Mean time to first rescue analgesia in Group $S$ was significantly longer $(9.07 \mathrm{hrs}$. v/s $1.50 \mathrm{hrs}$.). And total consumption of tramadol in first 24 hours was also significantly less in Group $S$ compared to Group C (58.06mg v/s 132.76mg).

Conclusion: Intercostal nerve block is an easy, safe and inexpensive method of analgesia and provides effective postoperative analgesia after standard PCNL.

Keywords: PCNL, Intercostal Nerve Blockade, Post-operative pain scores.
\end{abstract}




\section{Introduction:}

Renal Stones are relatively common and have a high rate of recurrence with $50 \%$ of patients developing recurrent stones in next 10 years ${ }^{[1,2]}$. Currently Percutaneous nephrolithotomy (PCNL) is the treatment of choice for large kidney stone burden as well asstaghorn calculus as it offers better stone free rates than Shock Wave Lithotripsy (SWL) and lower morbidity than open stone surgery ${ }^{[3,4]}$. The techniques used in PCNL have improved drastically with miniaturization of instruments and use of laser lithotripters leading to improved post-operative pain profile. Many studies have reported on the benefit of decreasing the size of the nephrostomy tubes used and tubeless surgeries ${ }^{[5]}$. But in Standard PCNL, still with the use of bigger dilators and Amplatz sheath, post-operative pain can be quite severe. Pain usually arises due to dilatation of renal capsule and renal parenchyma, extra vasation of fluid and indwelling nephrostomy tube. And it cannot be overemphasized that adequate analgesia in the postoperative phase not only decreases complications but also facilitates faster recovery. Intercostal nerve blockade (INB), a wellestablished form of regional anesthesia offers another option to decrease morbidity, analgesic requirements and hospitalization time post PCNL.

\section{Aim}

Through present study, we sought to evaluate the role of inter costal nerve blockade in Standard PCNL in terms of post-operative recovery, analgesia requirement, speed of mobilization and inpatient stay.

\section{Materials and Methods}

The study was conducted on patients who underwent Standard PCNL for urolithiasis in our department. A prospective cohort study was conducted on 60 patients aged between 18 to 60 years. Institutional ethical approval and informed consent were obtained. Patients were divided in two groups, group S or study group $(0.25 \%$ bupivacaine infiltration) consisting of 31 patients and group $\mathrm{C}$ or control group (without infiltration) consisting of 29 patients.

Exclusion criteria: Patients with a history of local anesthetic allergy, patients who required more than one puncture, patients who required supracostal puncture, patients with significant residual stones, patients having a psychiatric disorder or a history of alcohol or substance abuse, any cognitive disorder (i.e. dementia, Alzheimer's disease) or additional oncological disease were excluded.

PCNL was performed with single infracostal puncture. Standard 30 Fr Amplatz sheath and dilator set were used. 16 Fr Nephrostomy tube was placed in all patients at the end of the procedure. Analgesia in the form of opioids or NSAIDs was avoided during the entire procedure. The three inter costal nerves supplying the dermatomes within which the incisions were made were blocked with $5 \mathrm{ml}$ of $0.25 \%$ bupivacaine each in group $\mathrm{S}$ while in control group no infiltration was done. Postoperative pain was assessed by visual analogue scale (VAS) at rest \{score between 0 and 10$\}$ and dynamic visual analogue scale (DVAS) during deep breathing and coughing \{score between 0 and 10 \} every 4 hours for the first 24 hours. In visual analogue scale, 0 means no pain and 10 means maximum intolerable pain. When VAS score was $>4$, intravenous tramadol was given in a dose of 1 $\mathrm{mg} / \mathrm{kg}$ as a rescue analgesic. The total requirement of tramadol within 24 hours and any side effects such as nausea, vomiting, and sedation were noted.

The data collected included operative time, postoperative pain scores, post-operative analgesic requirements, inpatient stay and other demographic details. The patient pain scores and analgesic requirements as well as data concerning time to mobilization and hospital stay were entered into an Excel spreadsheet.

\section{Statistical Analysis}

Statistical analysis was performed using SPSS version 22. Data were expressed as mean with 
95\% confidence intervals (CIs) for continuous variables. Comparison of continuous variables was done using independent t-test with two tail significance. Categorical variables were compared using chi-square tests. "P" value $<0.05$ was considered significant.

\section{Results}

60 patients that underwent Standard PCNL were part of the study. 31 patients were included in Group-S whereas 29 patients were included in Group C. There were no dropouts or exclusions in the study. Table1 shows the group Sex Crosstabulation where both the groups were comparable. Table 2 shows group statistics regarding age, weight of the patients as well as the operative time for both the study and control group. On statistical analysis, no statistically significant difference was noted between the groups. Table 3 shows VAS and DVAS scores calculated at 4 hourly intervals for the first 24 hours. Scores were noted to be low at each interval for Group $\mathrm{S}$ compared to Group $\mathrm{C}$ but were statistically significant only till 16hours $(p<0.05)$ Mean time of first demand of pain killer was also significantly less ( $p<0.05)$ in study group with mean time of first demand being at $9.0 \pm 4.5$ hours compared to $1.5 \pm 1.4$ hours in the control group while total demand of pain killer in first 24 hours was also significantly less, being $58.06 \pm 41.02 \mathrm{mg}$ in study group and $132.76 \pm 30.69 \mathrm{mg}$ in the control group. Total duration of stay was also found to be significantly less in the study group compared to control group (3.77 \pm 0.6 days vs. $4.72 \pm 0.6$ days) because of early mobilization of the patient in the postoperative period.

Table 1: Cross Sex Tabulation

\begin{tabular}{|l|c|c|c|c|c|}
\hline \multicolumn{2}{|c|}{} & \multicolumn{2}{|c|}{ Sex } & \multirow{2}{*}{ Pearson Chi- Square test } \\
\cline { 3 - 4 } \cline { 3 - 4 } & \multirow{3}{*}{ Group S } & Male & Female & Total & P value \\
\cline { 3 - 4 } Group C & Count & $26(83.9 \%)$ & $5(16.1 \%)$ & 31 & \multirow{2}{*}{0.908} \\
\hline Total & & $5(17.2 \%)$ & 29 & \\
\hline
\end{tabular}

Table 2: Group Statistics

\begin{tabular}{|c|c|c|c|c|c|}
\hline & \multirow[t]{2}{*}{ Group } & \multirow{2}{*}{$\begin{array}{c}\text { No. of } \\
\text { patients }\end{array}$} & \multirow[t]{2}{*}{ Mean } & \multirow[t]{2}{*}{ Std. Deviation } & t-test for Equality of means \\
\hline & & & & & $\mathrm{P}$ value \\
\hline Age (years) & $\begin{array}{l}\mathrm{S} \\
\mathrm{C}\end{array}$ & $\begin{array}{l}31 \\
29\end{array}$ & $\begin{array}{l}43.65 \\
44.69\end{array}$ & $\begin{array}{l}10.301 \\
13.893\end{array}$ & 0.741 \\
\hline Weight (kg) & $\begin{array}{l}\mathrm{S} \\
\mathrm{C}\end{array}$ & $\begin{array}{l}31 \\
29\end{array}$ & $\begin{array}{l}61.42 \\
61.90\end{array}$ & $\begin{array}{l}10.604 \\
10.567\end{array}$ & 0.862 \\
\hline $\begin{array}{l}\text { Operative } \\
\text { (min) }\end{array}$ & $\begin{array}{l}\mathrm{S} \\
\mathrm{C}\end{array}$ & $\begin{array}{l}31 \\
29 \\
\end{array}$ & $\begin{array}{l}63.71 \\
69.31 \\
\end{array}$ & $\begin{array}{l}23.769 \\
21.577\end{array}$ & 0.344 \\
\hline
\end{tabular}

Table 3: Group Statistics

\begin{tabular}{|lc|c|c|c|}
\hline & Group & $\mathrm{N}$ & Mean & $\begin{array}{c}\text { t-test for Equality of Means } \\
\text { P value }\end{array}$ \\
\hline VAS $4 \mathrm{Hr}$ & $\mathrm{S}$ & 31 & 2.81 & .000 \\
\hline $8 \mathrm{Hr}$ & $\mathrm{C}$ & 29 & 8.07 & .005 \\
& $\mathrm{~S}$ & 31 & 4.48 & .026 \\
\hline $12 \mathrm{Hr}$ & $\mathrm{C}$ & 29 & 5.86 & .038 \\
& $\mathrm{~S}$ & 31 & 3.84 & \\
\hline $16 \mathrm{Hr}$ & $\mathrm{C}$ & 29 & 5.45 & .590 \\
& $\mathrm{~S}$ & 31 & 3.52 & .172 \\
\hline $20 \mathrm{Hr}$ & $\mathrm{C}$ & 29 & 4.45 & \\
\hline $24 \mathrm{Hr}$ & $\mathrm{S}$ & 31 & 3.35 & \\
\hline
\end{tabular}




\begin{tabular}{|lc|c|c|c|}
\hline & C & 29 & 3.72 & \\
\hline DVAS $4 \mathrm{Hr}$ & $\mathrm{S}$ & 31 & 3.48 & .000 \\
& $\mathrm{C}$ & 29 & 8.79 & .029 \\
\hline $8 \mathrm{Hr}$ & $\mathrm{S}$ & 31 & 5.45 & .047 \\
\hline $12 \mathrm{Hr}$ & $\mathrm{C}$ & 29 & 6.41 & .049 \\
& $\mathrm{~S}$ & 31 & 4.55 & .112 \\
\hline $16 \mathrm{Hr}$ & $\mathrm{C}$ & 29 & 6.24 & .195 \\
& $\mathrm{~S}$ & 31 & 4.13 & .001 \\
\hline $20 \mathrm{Hr}$ & $\mathrm{C}$ & 29 & 4.97 & .002 \\
\hline $24 \mathrm{Hr}$ & $\mathrm{S}$ & 31 & 4.06 & .001 \\
& $\mathrm{C}$ & 29 & 5.86 & \\
\hline Mean time of demand & $\mathrm{S}$ & 31 & 3.35 & \\
of 1 & $\mathrm{C}$ & 29 & 3.76 & \\
\hline Total Demain killer (Hrs.) & $\mathrm{S}$ & 26 & 9.07 & \\
(mg) & $\mathrm{C}$ & 29 & 1.50 & \\
\hline Total duration of stay (days) & $\mathrm{S}$ & 31 & 58.06 & \\
& $\mathrm{C}$ & 31 & 3.77 & \\
\hline
\end{tabular}

\section{Discussion}

Since the time first percutaneous stone extraction was done by Fernström \& Johannson ${ }^{[6]}$, there has been drastic improvement in PCNL techniques with recent innovations like miniperc ${ }^{[7,8,9]}$, microperc and ultra-miniperc. Skin incisions have become smaller, smaller amplantz sheaths and laser lithotripters are being used for stone clearance. But in many Government institutions Standard PCNL is still being practiced with standard dilator set and 30 Fr Amplantz sheath and post-operative pain can be severely disabling. Several techniques have been used for optimization of pain control post PCNL. Trivedi et $\mathrm{al}^{[10]}$ reported use of inter pleural block for PCNL with $0.5 \%$ bupivacaine and found that the mean duration of pain relief was for $10 \mathrm{hrs}$ while Jonnavithula et $\mathrm{al}^{[11]}$ studied the efficacy of peritubal local anesthetic infiltration in alleviating postoperative pain in PCNL and showed decreased pain scores with infiltration of the nephrostomy tract with $0.25 \%$ bupivacaine. Tubeless PCNL is also being used in selected group of patients with stone burden $<3 \mathrm{~cm}$, single tract access, no significant residual stones, no significant perforation, minimal bleeding, and no requirement for a secondary procedure with significant reduction of pain scores postoperatively ${ }^{[5]}$. Other option being used is INB. The use of INB has been described in the wider literature for over 50 years. It is simple to perform and has been shown to reduce analgesic requirements and inpatient stay in a variety of operative scenarios, such as thoracic and cardiac surgery. Use of INB in urology has been reported with good effect in some studies for open flank incisions and renal transplant surgery ${ }^{[12,13]}$. Haleblian et $\mathrm{al}^{[14]}$ showed reduced rescue analgesic requirement with $0.25 \%$ bupivacaine skin infiltration but no significant difference in pain scores while Viney et al ${ }^{[15]}$ did a comparative cohort study for perioperative Inter costal nerve blockade in PCNL and concluded that it significantly improves pain scores. Parikh et al ${ }^{[16]}$ demonstrated higher duration of analgesia with ropivacaine infiltration of peritubal tract compared to bupivacaine (10.54 hrs. vs. $7.1 \mathrm{hrs}$.).Here, in our study we have evaluated the efficacy of inter costal nerve block with use of $0.25 \%$ bupivacaine in cases where Standard PCNL was done and found that the results were comparable to Viney et al study where INB provides effective analgesia in immediate post-operative period with significantly lower pain scores and significantly higher mean time for first rescue dose of analgesia $(9.07 \mathrm{hrs}$. vs. $1.5 \mathrm{hrs}$.). Total demand of pain killers in first 24 hours was also assessed and found to be significantly less in Study group compared to control group. There were no complications noted in post-operative period attributable to INB itself. 
Limitations of our study were that we included only patients with single puncture and single nephrostomy tube, thus being unable to evaluate efficacy of INB in complex cases with multiple punctures with multiple nephrotomies placement. So we advocate a suitably powered prospective study to explore the value of INB further.

\section{Conclusion}

Our randomised controlled study for evaluating the role of inter costal nerve blockade in Standard PCNL in terms of post-operative recovery, analgesia requirement and speed of mobilization suggested that INB in a standard PCNL with larger skin incision and bigger Amplatz sheath and tract dilators provides an easy, safe and inexpensive method of analgesia and significantly improves post-operative pain scores. We also concluded that this practice led to significantly reduced analgesic and opioids requirements and longer pain free period without any adverse effects attributable to INB itself. The technique is easy to learn and uses both palpation of bony landmarks and fluoroscopy to aid delivery of anesthetic. So, INB with bupivacaine infiltration may be recommended as a routine in all institutions where Standard PCNL is being practiced to optimize pain control.

\section{Sources of Funding: Nil \\ Conflicts of Interest: None}

Acknowledments: We are highly indebted to our patients for consenting for this study.

Contribution Details: All authors have participated sufficiently in the intellectual content, conception and design of this work as well as the writing of the manuscript

\section{References}

1. Trinchieri A, Ostini F, Nespoli R, Rovera F, Zanetti G. A prospective study of recurrence rate and risk factors for recurrence after a first renal stone. J Urol 1999;162:27-30.
2. Sutherland JW, Parks JH, Coe FL. Recurrence after a single renal stone in a community practice. Miner Electrolyte Metab 1985;11:267-9.

3. Miller NL, Lingeman JE. Management of kidney stones. BMJ 2007;334:468—72.

4. LeRoy AJ, Segura JW, Williams HJ, Patterson DE. Percutaneous renal calculus removal in an extracorporeal shock wave lithotripsy practice. J Urol 1987;138(703).

5. Madhu Sudan Agrawal, Mayank Agrawal, Tubeless percutaneous nephrolithotomy, Indian J Urol. 2010 Jan-Mar; 26(1): 1624.

6. Fernström I, Johannson B. Percutaneous pyelithotomy.A new extraction technique. Scand J Urol Nephrol 1976;10(257).

7. Chan DY, Jarrett TW. Mini-percutaneous nephrolithotomy. J Endourol 2000;14:269-73.

8. Jackman SV, Docimo SG, Cadeddu JA, Bishoff JT, Kavoussi LR, Jarrett TW. The "mini-perc" technique: A less invasive alternative to percutaneous nephrolithotomy. World J Urol 1998;16:371-4.

9. Monga M, Oglevie S. Mini percutaneous neph or lithotomy.J Endourol 2000;14:419-21.

10. Trivedi NS, Robalino J, Shevde K. Interpleural block: a new technique for regional anaesthesia during percutaneous nephrostomy and nephrolithotomy. Can J Anaesth 1990;37(May (4 Pt 1)):479-81.

11. Jonnavithula N, Pisapati MV, Durga P, Krishnamurthy V, Chilumu R, Reddy B. Efficacy of peritubal local anesthetic infiltration in alleviating postoperative pain in percutaneous nephrolithotomy. $\mathrm{J}$ Endourol 2009;23:857-60.

12. Noller DW, Gillenwater JY, Howards SS, Vaughan Jr ED. Intercostal nerve block with flank incision. J Urol 1977;117(June (6)):759—61. 
13. Knowles P, Hancox D, Letheren M, Eddleston J. An evaluation of intercostal nerve blockade for analgesia following renal transplantation. Eur J Anaesthesiol 1998;15(July (4)):457-61.

14. Haleblian GE, Sur RL, Albala DM, Preminger GM. Subcutaneous bupivacaine infiltration and postoperative pain perception after percutaneous nephrolithotomy. J Urol 2007;178:925-8.

15. R. Viney, H. Garston, P. Patel, R. Devarajan. Perioperative intercostal nerve blockade in percutaneous nephrolithotomy A comparative cohort study. British Journal of Medical and Surgical Urology (2010) 3, 106-110

16. Geeta P Parikh, Veena R Shah, Kalpana S Vora, Beena K Parikh, Manisha P Modi, Pratibha Kumari. Peritubal infiltration in percutaneous nephrolithotomy. Indian Journal of Anaesthesia | Vol. 58 | Issue 3 | May-Jun 2014. 